\title{
Running out of staff for the NHS
}

\author{
Reductions in school leavers plus Project 2000 may bring the NHS to its knees
}

Between 1983 and 1993 the number of school leavers will fall by about a third, and most of this fall will occur in the next four years. The decline will last through the $22 \%$ increase in those aged over 75 and will place an enormous strain on the NHS. Indeed, the problem is so serious that the text of a presentation on this topic to the regional manpower planners' group was entitled 2001-The Black Hole: an Examination of Labour Market Trends in Relation to the National Health Service.' Although the report focuses on the labour market for the 14 English regions, the demographic projections for Scotland and Wales show similar trends. The problem is much worse than has been envisaged. Moreover, the remedies that have already been proposed (including improving retention rates and widening entry gates) will not on their own provide the solution. The growth in demand for services has already been projected in regional strategic plans - as has the predicted need for substantial increases in the qualified workforce.

The NHS relies heavily on recruiting school leavers, and there will probably be a greater reduction in working entrants to the NHS than the drop of a third in 18 year olds. Indeed, in 1982-3 when the number of school leavers was at its peak the numbers entering nursing had already begun to decline. Since then there has been an almost $30 \%$ reduction in the numbers entering nursing training. Trends in radiography have been worse; in 1987 radiography schools achieved only half of their target intakes. In nursing, radiography, and occupational therapy (all disciplines in which district hospitals have long recognised staffing difficulties) the full impact of the problem has not been appreciated and still permits complacency. This is because there are qualifiers from past intakes - but nowhere near enough to carry us through "the black hole." NHS professionals allied to medicine are predominantly $(90 \%)$ women, and they come from a narrow educational band with five $\mathrm{O}$ levels and two A levels (18\% of the labour market), which is further reduced by those who enter universities or other colleges.

The NHS is already entering an impossible position. In 1983 it recruited the equivalent of $43 \%$ of the labour market in suitably qualified women; by 1993 the share of the market required will be $62 \%$. Furthermore, this figure has been calculated at intakes consistent with 1986, when entry had fallen below target levels. The male population of working age will show an even greater reduction than the female population, meaning that there is little scope for improving
NHS recruitment when other non-NHS service industries are hungry for their own labour force-both male and female.

Another important component of the NHS staffing problems is the nursing project, Project 2000, established in 1984 by the United Kingdom Central Council for Nursing, Midwifery, and Health Visiting (UKCC) as the statutory body responsible for regulating these professions. After a series of project papers seeking to clarify options the council published in May 1986 its main consultation report-Project 2000: a New Preparation for Practice. ${ }^{2}$ The council's proposals were formally received by British health ministers in February $1987 .{ }^{3}$ The key issue is "the proposed change of status of the student nurse from salary to bursary and from the present arrangements to a lower service contribution during training." The complications of this are best taken from project paper eight, which states: "The shortfall [to nursing] of 3000 entrants in 1994 without Project 2000 rises to 16000 with it." The serious demographic implications for shortages of nurses are well considered in project paper nine, ${ }^{6}$ which states that nursing needs to recruit about 30000 additional staff each year in Britain. Though no one would deny that there is a case for educational change in nursing, midwifery, and health visiting, Project 2000 will, if implemented, bring the NHS to its knees - at a time when the government through its NHS reforms will have already delegated its responsibility and its accountability to the nation to doctors.

Another problem is that in 1992 we will need to face our European neighbours once again. They have their own impending labour market problems. This perhaps underlines their recent insistence that our schoolchildren should be compulsorily taught at least two foreign languages.

A cynic might suggest that the recent conflicts between the government and the doctors may have been engineered by the government to provide a smokescreen for these impending disasters. The ultrashort timescale of the NHS reforms may allow the government to get out from underneath well before the effects of a contracting labour market further frustrates the health service. The blame for any collapse of services that may occur-particularly in the run up to the next general election - could be laid at the door of doctors.

The words of Dr John Marks, chairman of BMA council, that have been addressed to Mr Kenneth Clarke, Secretary of State for Health, are therefore appropriate; "Sit down, slow down, and listen." To these could be added, "Let us work together and this time do not force change from the 'top down' 
because of political panic, but, let us lead it from the 'bottom up' because we can see the problems and wish to contribute to the solutions."

University of London's Professor in

BRIAN LIVESLEY

the Care of the Elderly,

Charing Cross and Westminster

Medical School,

London W6 8RP

1 Conroy M, Stidston M. 2001-The black hole: an examination of labour market trends in relation to the National Health Service. London: South West Thames Regional Health Authority, 1988.

2 United Kingdom Central Council for Nursing, Midwifery, and Health Visiting. Project 2000: a new preparation for practice. London: UKCC, 1986.

3 Peach L. UKCC Project 2000: health department consultation. London: NHS Management Board. (Letter sent to general managers of regional, district, and special health authorities, 6 March 1987.)

4 Peach L. UKCC Project 2000: health department consultation. London: NHS Management Board. (Annexe to letter sent to managers of regional, district, and special health authorities, 6 March 1987.

5 United Kingdom Central Council for Nursing, Midwifery, and Health Visiting. Project Paper 8 : Counting the cost; is Project 2000 a practical proposition. London: UKCC, 1987:7.

6 United Kingdom Central Council for Nursing, Midwifery, and Health Visiting. Project Paper 9 Project 2000; a final protocol. London: UKCC, 1987:11.

\section{Screening for antibodies to anaesthetics}

\section{No case for doing it yet}

Anaphylactoid reactions occur in between one in 5000 and one in 20000 anaesthetics, and death occurs in about $4 \%$ of these reactions. Most reactions are caused by intravenous anaesthetics and muscle relaxants and occur during induction of anaesthesia. ${ }^{1}$ There are now radioallergosorbent tests that identify IgE antibodies reacting with some anaesthetic drugs (thiopentone, suxamethonium, and alcuronium). ${ }^{2}$ These tests may be used for investigating anaphylactoid reactions and for screening before anaesthesia. ${ }^{3}$ Their use for screening has recently been boosted by a statement made by Sheriff Kelbie of Aberdeen in a fatal accident inquiry, but their use in this way is fraught with problems and needs careful examination.

The inquiry followed the death of a young mother who apparently suffered anaphylaxis induced by suxamethonium, although she had received the drug safely more than once before. The Sheriff recommended that "health boards should consider screening people coming on to their waiting lists for elective surgery at the initial consultation, particularly where the patient is female, has previously had suxamethonium as part of anaesthesia and/or has shown signs of other allergy."

At the moment sensitivity to only three anaesthetic drugs may be tested by radioallergosorbent tests, and only some anaphylactoid reactions during anaesthesia are mediated by IgE. ${ }^{156}$ Reported studies have given results on only a few patients, and the validity and accuracy of radioallergosorbent tests remain to be ascertained-even among populations that have had anaphylactoid reactions and in which clinical details are known. Such studies are prone to sampling, measurement, and reporting bias, which often result in an overestimate of the test's usefulness. ${ }^{7}$ Moreover, even a test that is useful in investigating patients who.have suffered reactions might perform poorly as a screening test. ${ }^{7}$ The positive predictive value of a test depends on the prevalence of the abnormality to be detected. ${ }^{8}$ Thus in a population with a low prevalence of abnormality even a highly specific test will detect a few true positives and many false positives ${ }^{9}$ : if the prevalence of abnormality is one in 10000 a test with $100 \%$ sensitivity and $95 \%$ specificity would generate 500 false positives for each true positive. Many patients might thus have an unnecessary fear of anaesthesia and might also-because of restrictions in drug selection-receive suboptimal anaesthesia. Cross reactivity between relaxants and false positive results in patients with raised plasma IgE concentration must also be considered. ${ }^{10-13}$

Apart from patients with a history of adverse reactions to anaesthesia there is no clearly identifiable subgroup which would merit testing. A history of atopy is not predictive, ${ }^{1+16}$ and a history of previous exposure to particular drugs is unlikely to be helpful: nine out of 10 patients in one study who reacted to suxamethonium did so on first exposure to the drug. ${ }^{10}$ The screening would have important medicolegal ramifications and might encourage more defensive medical practice.${ }^{17}$ Finally, the cost of a mass screening programme might be enormous: the cost of testing for each individual drug is about $£ 1$. There would have to be increases in staffing and resources at clinics and in laboratories to perform the tests, and there would be the costs of follow up and counselling of patients with positive results.

These problems must be answered before routine screening with radioallergosorbent tests would be sensible, and data from prospective studies are required to assess its potential usefulness. ${ }^{18}$ At present there seems to be little justification for its introduction in mass screening. Deaths from anaphylaxis may be' reduced by taking an adequate drug history thus avoiding giving for a second time a drug that has already precipitated an adverse reaction. Such catastrophes do occur. ${ }^{1920}$ The management of anaphylactoid reactions is sometimes poor ${ }^{21}$ - possibly because of the rarity of such events. Anaesthetists in training should be taught to rehearse an "anaphylaxis drill."

D W NOBLE

Lecturer in Anaesthetics

Department of Anaesthetics,

Royal Infirmary,

Edinburgh EH3 9YW

Edinburgh and South East Scotland Blood Transfusion Service,

Royal Infirmary,

Edinburgh EH3 9HB

1 Fisher MM, Baldo BA. Anaphylactoid reactions during anaesthesia. Clinics in Anaesthesiology 984;2:667-92

2 Moudgil GC. Anaesthesia and allergic reactions. Canadian Anaesthetists Society fournal 1986 33:406.

3 Assem ESK, Ling YB. Fatal anaphylactoid reaction to suxamethonium: new screening tes suggests possible prevention. Anaesthesia 1988;43:958-61.

4 Sheriff Kelbie, Sheriffdom of Grampian, Highlands and Islands. Determination given on 9 May 1989 at Aberdeen.

5 Simpson PJ. Adverse reactions to intravenous anaesthetic agents. Clinics in Anaesthesiology 1984;2:185-201.

6 Ring J. Colloids. Clinics in Anaesthesiology 1984;2:628-30.

7 Browner WS, Newman TB, Cummings SR. Designing a new study: III. Diagnostic tests. In Hulley SB, Cummings SR, eds. Designing clinical research. Baltimore: Williams and Wilkins, 1988: 87-97.

Vecchio TJ. Predictive value of a single diagnostic test in unselected populations. $N$ Engl F Med 966;274:1171-3.

Fletcher RH, Fletcher SW, Wagner EH. Clinical epidemiology:-the essentials. Baltimore: Williams and Wilkins, 1982:41-74.

10 Harle DG, Baldo BA, Fisher MM. Detection of IgE antibodies to suxamethonium after anaphylactoid reactions during anaesthesia. Lancet 1984;i:930-2.

11 Didier A, Cador D, Bongrand P, et al. Role of the quaternary ammonium ion determinants in allergy to muscle relaxants. F Allergy Clin Immunol 1987;79:578-84

12 Dueck R, O'Connor RD. Thiopental: False positive RAST in patients with elevated serum IgE. Anesthesiology 1984;61:337-8.

13 Assem ESK. Tests for detecting drug allergy. In: Davies DM, ed. Textbook of adverse reactions. London: Oxford University Press, 1985:642-3.

14 Fisher MM, Roffe DJ. Allergy, atopy and IgE. The predictive value of total $\operatorname{IgE}$ and allergic history in anaphylactic reactions during anaesthesia. Anaesthesia 1984;39:213-7.

15 Fisher $M M$, Outhred A, Bowey CJ. Can clinical anaphylaxis to anaesthetic drugs be predicted from allergic history? Br f Anaesth 1987;59:690-2.

16 Charpin D, Benzarti M, Hemon Y, et al. Atopy and anaphylactic reactions to suxamethonium. Allergy Clin. Immunol 1988;82:356-60.

17 Forrest JB. Defensive medicine: anaesthetic practice in the 80s. Anaesthesia 1984;39:1165-7.

18 Sackett DL, Haynes RB, Tugwell P. Clinical epidemiology. Boston: Little Brown, 1985:47-57

19 Youngman PR, Taylor KM, Wilson JD. Anaphylactoid reactions to neuromuscular blocking agents: a commonly undiagnosed condition? Lancet 1983;ii:597-9.

20 Fisher MM. The prevention of second anaphylactoid reactions to anaesthetic drugs. Anaesth Intensive Care 1981;9:242-6.

21 Fisher MM. Anaphylaxis. Anaesthesia 1989;44:516-7. 